\section{TEACHING AND TEACHER EDUCATION}

www.elsevier.com/locate/tate

\title{
Promoting versatility in mentor teachers' use of supervisory skills
}

\author{
Frank Crasborn ${ }^{\mathrm{a}, *}$, Paul Hennissen ${ }^{\mathrm{a}}$, Niels Brouwer ${ }^{\mathrm{b}}$, Fred Korthagen ${ }^{\mathrm{c}, \mathrm{d}}$, \\ Theo Bergen ${ }^{\mathrm{e}, \mathrm{f}}$ \\ ${ }^{a}$ Department of Teacher Education, Fontys University of Applied Sciences, P.O. Box 558, 6130 AN Sittard, The Netherlands \\ ${ }^{\mathrm{b}}$ ILS, Graduate School of Education, Radboud University, Nijmegen, The Netherlands \\ ${ }^{\mathrm{c}}$ Vrije Universiteit, Amsterdam, The Netherlands \\ ${ }^{\mathrm{d}}$ Utrecht University, Utrecht (NL), The Netherlands \\ ${ }^{\mathrm{e}}$ ILS, Graduate School of Education, Radboud University, Nijmegen, The Netherlands \\ ${ }_{\mathrm{f}}^{\mathrm{f}}$ Eindhoven School of Education, University of Technology, Eindhoven (NL), The Netherlands
}

Received 2 June 2006; received in revised form 20 April 2007; accepted 16 May 2007

\begin{abstract}
Mentor teachers need a versatile supervisory skills repertoire. Besides taking the prevalent role of daily advisor and instructor, mentor teachers should also be able to stimulate reflection in student teachers. Video recordings of 60 mentoring dialogues were analysed, both before and after a mentor teacher training aimed at developing the encourager role. Mentor teachers' repertoires of supervisory skills were found to consist of an average of seven supervisory skills. After training, a shift was observed in the frequencies and duration with which supervisory skills were used. Although considerable inter-individual variability existed between mentor teachers, training positively affected the use of supervisory skills for stimulating reflection in student teachers.
\end{abstract}

(C) 2007 Elsevier Ltd. All rights reserved.

Keywords: Mentoring; Mentor training; Mentoring dialogue; Supervisory skills; Mentor teacher; Reflection

\section{Introduction}

One essential condition for student teachers to learn in the workplace is the availability of effective guidance by and cooperation with a mentor teacher whose approach matches the learning needs of the prospective teacher (Williams et al., 1998). This places great demand on the professionalism of

\footnotetext{
*Corresponding author. Tel.: + 31877879568 ; fax: +31877875500 .

E-mail address: f.crasborn@fontys.nl (F. Crasborn).
}

mentor teachers in encouraging student teachers to learn from their practical experiences in the school setting. In practice, mentor teachers' supervisory styles are manifested in large part in the intentions, the approach and the contents of their dialogues with student teachers. In these respects, mentor teachers have a considerable influence on how and what student teachers learn (Feiman-Nemser, 2000).

Mentor teachers are usually inclined to take the role of daily advisor and instructor to the student teacher (Dunn \& Taylor, 1993; Field \& Field, 1994; Franke \& Dahlgren, 1996; Haggarty, 
1995; Timperley, 2001). Apart from this mentor teacher role, which emphasizes situational adjustment, technical advice and emotional support, mentoring in the nineties gradually also came to include the encouragement of the student teacher to grow professionally through reflection on his or her own practice (Feiman-Nemser, 2001; McLennan, 1995; Pajak, 1993). Teacher training institutes and schools nowadays want mentor teachers to be capable also of promoting reflection and personal development in prospective teachers entrusted to their responsibility (Gore \& Zeichner, 1991; Rodgers, 2002). Combining the advisor and instructor role with the role of encourager of reflection, however, often requires special training in less familiar supervisory skills.

In order to develop mentor teachers' supervisory skills, which activate reflection in student teachers, many teacher education institutions and schools have introduced training programmes (Strong \& Baron, 2004). So far, little is known about the practical impact of such training programmes (Riggs, 2000). The core issue in this study is developing a versatile repertoire of supervisory skills, to be used by mentor teachers in their mentoring dialogues with aspiring colleagues. The main incentive for the research reported on here was to broaden the body of knowledge concerning the contribution of supervisory skills training to the professional development of expert teachers in their position as mentor teachers. In the context of the developmental-reflective paradigm in mentoring, we investigated whether and how training in supervisory skills for promoting reflection affects the supervisory behaviour of mentor teachers during dialogues with student teachers.

\subsection{Wanted: a versatile repertoire of supervisory skills}

Several researchers have drawn attention to the multiplicity and complexity of the position as a mentor teacher and to the potential conflicts between several roles within this position (Dart \& Drake, 1995; Martin, 1996). “... Of general agreement is the reality that mentoring is multi-faceted and has no simple prescription or recipe for success..." (Harrison, Lawson, \& Wortley, 2005, p. 425). One important aspect of the complexity of the mentor teacher position is the need to achieve a good match between his or her approach on the one hand, and learning characteristics of the student teacher on the other. Mentor teachers therefore need to develop a versatile repertoire of supervisory skills to use in mentoring dialogues (Veenman \& Denessen, 2001; Vonk, 1993) for a number of reasons. Student teachers have different learning styles, which partially depend on their orientations towards learning (Korthagen, 1988; Oosterheert \& Vermunt, 2001). It is also known from research that student teachers' professional development takes place at differing speeds, and thus their needs and concerns change over time. This is true for student teachers (Furlong \& Maynard, 1995) and also for teachers at the start of their professional careers (Kagan, 1992). Finally, it is vital that mentor teachers have a broad supervisory skill repertoire as the nature of the relationship between the mentor teacher and the mentee is fluid and liable to change (Martin, 1994).

Despite this call for flexibility in the mentoring approach, many mentor teachers see and practise their position more as an advisor and instructor who gives instructions, suggestions and moral support, than as an encourager of reflection on concrete thoughts and actions in the classroom (Borko \& Mayfield, 1995; Feiman-Nemser, 2000; Franke \& Dahlgren, 1996; Van Ginkel, Vermunt, Verloop, \& Beijaard, 2005). Research by Copeland (1982) and Williams et al. (1998) suggest that mentor teachers hardly change their supervisory styles in response to the changing needs of students. This indicates that mentor teachers, either consciously or subconsciously, stick to a certain supervisory style, notably the advisor role.

As student teachers' behaviour in the school is to be shaped and influenced, it is not enough for them to receive instruction, to obtain feedback, to be given suggestions and to be shown examples of good practice. In order to develop as a professional, it is necessary to be able to reflect on your own behaviour (Borko \& Putnam, 1995; de Jong, 2004; Korthagen, 1998, 2001; Licklider, 1995; Veenman \& Denessen, 2001; Vonk, 1996). This means that in addition to the prevalent role of advisor and instructor, mentor teachers have to develop knowledge of and supervisory skills in being effective in stimulating the student teacher towards reflection (Boydell, 1991; Giebelhaus \& Bowman, 2002). Mentor teachers therefore need a versatile supervisory skills repertoire. Because of the individual differences in development between student teachers mentioned earlier, setting a norm for the required mix of existing supervisory skills and newly learned 
skills during supervisory skills for mentor teachers to activate reflection in teachers (SMART) training is not useful. The right combination of "old" and "new" supervisory skills depends on the specific mentoring situation.

\subsection{Supervisory skills in the developmental-reflective paradigm}

The aspect of reflection in supervising student teachers is seen by Pajak (1993) as characteristic of the most recent of four consecutive generations of approaches in "clinical supervision". In chronological order he describes "original clinical models" (Goldhammer, 1969), "humanistic-artistic models" (Blumberg, 1980), "technical-didactic models" (Joyce \& Showers, 1982) and "developmentalreflective models" (Costa \& Garmston, 1994). The latter is still current. A shift has taken place from a technical, rationalistic view of teaching as mastery of subject knowledge and discrete pedagogical skills to one which recognizes that teaching is a relatively unpredictable and cognitively complex activity, characterized by decision making, negotiation for meaning and reflection in action. Also, there is increasing scientific recognition of the value of learning in the workplace (Eraut, 2000). In addition, the relevance of theory in teacher education programmes as a preparation for practice has been criticized (Koetsier \& Wubbels, 1995). Finally, we are faced with growing teacher shortages in the industrialized world, where teachers are trained within shorter time span to become independent practising teachers. All the trends place great demand on student teachers being able to reflect on and learn from their practical experiences.

The assumption behind the prevalent developmental-reflective paradigm in mentoring (student) teachers is that teachers who are able to complete reflective cycles by themselves are empowered to learn from their own practice, to cope with change and to give direction to their learning (Korthagen, 2001; Laboskey, 1994). This type of reflection does not come about by itself. In order to stimulate reflection in student teachers, mentor teachers need to put into practice a number of specific supervisory skills. Situated within the reflective-developmental paradigm, qualities and skills that have to do with the mentor teacher role of encourager of reflection are often based on literature about training for supervision and therapy (Brammer, 1973; Carkhuff, 1969; Egan, 1975; Rogers, 1969).
On this basis, Korthagen (1985, 2001) distinguishes overt supervisory skills to stimulate reflection in student teachers: asking for concreteness, summarizing feeling (showing empathy), showing genuiness, generalizing (asking for similar situations), helping in making things explicit, confronting (giving feedback, summarizing inconsistencies, utilizing the here and now) and helping to find and to choose alternatives. These skills can be used to encourage a cyclical sequence of five steps (ALACT model), which together constitute a complete reflection process: Action (1); looking back on the action (2); becoming aware of essential aspects (3); creating alternative methods of action (4); and engaging in a new trial (5). The last step of one cycle is the first step of the following cycle. Combining supervisory skills distinguished and described by Blumberg (1980), Glickman (1981) and Vrolijk (1991) resulted in the following descriptions of overt supervisory skills associated with the mentor teacher role of advisor and instructor: asking for something new, giving information, giving opinion/assessing and giving advice/instruction.

All in all, to be able to label all supervisory behaviour of mentor teachers in mentoring dialogues, we distinguished the following repertoire of 15 supervisory skills: showing attentive behaviour (1), asking an open starting question (2), asking for concreteness (3), summarizing feeling (showing empathy) (4), summarizing content (5), showing genuineness (6), completing sentence/clarifying question (7), confronting (giving feedback, summarizing inconsistencies, utilizing the here and now) (8), generalizing (asking for similar situations) (9), helping in making things explicit (10), helping in finding and choosing alternatives (11), asking for something new (12), giving information (13), giving opinion/assessing (14), and giving advice/instruction (15).

\subsection{Scarcity of effect studies}

In the context of training and supervising teachers, quite some research has been done on how mentor teachers function (Hawkey, 1998). In these studies, the form, the content and the procedure of the mentoring dialogues have been analysed. However, very few studies are available concerning the observable effects of training on the use of supervisory skills by mentor teachers in authentic mentoring dialogues with student teachers. Veenman and Denessen (2001) summarize findings of five studies evaluating the effects of 
training programmes focusing on supervisory skills for teacher coaches. Significant effects were found for supervisory skills concerned with the development of autonomy (empowerment), feedback and encouragement of self-reflection. Koster, Wubbels, Korthagen, and Somers (1996) report limited positive effects of a training programme on the supervisory behaviour of mentor teachers. The measures used in this study were restricted to selfreports. Also, learning effects on the level of attitude changes and self-perceptions have been demonstrated, although limited in size.

Research by Evertson and Smithey (2001) showed that trained mentor teachers demonstrated better conferencing skills, including more awareness of student teachers' needs to analyse their own teaching before being offered solutions. They found that trained mentor teachers guided their protégés more to use self-inquiry or self-discovery in reflecting on a lesson as opposed to evaluating or giving advice for improvement. Trained mentor teachers also used more active listening skills as opposed to a passive listening and trained mentor teachers elicited more reflection through probing or using follow-up questions. Timperley (2001) concluded that after training mentor teachers were able to improve the quality of their dialogues with their student teachers. Analysis of audio-taped transcripts of mentoring dialogues revealed that before training a common pattern for mentor teachers was to give direct advice about how to overcome undisclosed concerns about student teachers' practice. After training, mentor teachers were able to promote more the student teachers' professional development: they more frequently disclosed their concerns, checked to see whether their concerns were shared and engaged the student teachers' personal theories about their reasons for practising in the way they did before developing joint solutions. Strong and Baron (2004) analysed how mentor teachers make pedagogical suggestions to beginning teachers during mentoring dialogues. They concluded that mentor teachers made extreme efforts to avoid giving direct advice to novice teachers and used a corpus of interventions that include many indirect suggestions, about one-third of which produce elaborate responses from the novice teachers. This finding was mainly attributed to the training programme that all mentor teachers received based largely on the 'cognitive coaching model' (Costa \& Garmston, 1994). Research by Harrison et al. (2005) illustrated that mentor teacher training that focuses on the processes concerned with the types of questioning by the mentor teacher which enables the mentee to begin to open themselves up for scrutiny, can begin to create different ways of working. The mentee is then able to become autonomous in analysing situations arising in practice, and also in thinking of alternative ways of dealing with them.

Edwards and Green (1999) conclude in a study that 'cognitive coaching' training can stimulate growth in the supervisory skills and in the reflection level of teachers because mentor teachers were talking less, were less directive, gave the teacher the opportunity to open the dialogue and sought to draw out the answers from the teachers. There were also individual differences. Not all mentor teachers showed growth in their skills and neither did all the teachers in their level of reflection. Hence, the results of this last study emphasize the fact that all participants do not experience the same effects from a training. This may be caused by the fact that the training content and approach is often the same for all participants, while their needs and skill level were possibly different. Training is not working out the same for every participant. There is a potential influence of personal characteristics of each trainee and also of features and facilities of the workplace (Holton \& Baldwin, 2000). Studies into the effects of training on the supervisory repertoire of mentor teachers should therefore also map individual differences, in addition to the average effects on the whole group.

\subsection{Capturing supervisory behaviour}

In the cited studies, effects of training are reported to varying degrees. However, the available empirical evidence is still limited and too diverse to allow drawing definite conclusions about the influence of mentor teacher training on the use of supervisory skills activating reflection in student teachers. The available studies are diverse with regard to focus and approach of the evaluated training programmes, the concepts employed, the type and size of respondent groups as well as the operationalization and observation methods of the studied supervisory skills. Therefore, more effect evaluation studies, specifically in the field of teacher mentoring, are needed.

From a methodological point of view, it is interesting to note that in most studies only a restricted range of supervisory skills, notably those 
practised during training, are observed. The nature of the relationship of the trained skills with those not specifically trained is not taken into account. It is known from Gestalt psychology that we cannot regard new behaviour as really present until new Gestalts are sufficiently linked to it and can for that reason compete with those Gestalts that are linked to the old behaviour. A Gestalt denotes a behaviour tendency, with the associated subconscious needs, values, experiences and concepts, which are called up when faced with a certain situation (Dolk, 1997).

In order to achieve insight into the impact of training in the use of supervisory skills, not only a selection of skills practised in particular training programmes should be observed, but also a broader repertoire of supervisory skills usable in mentoring dialogues should be investigated. This is what was attempted in this study. In addition, to observe how supervisory behaviour may develop in mentor teachers, we need to look at any changes between pre- and post-training measurements of behaviour in mentoring dialogues.

An important aspect of the operationalizations used in the available studies on mentor teachers' dialogues with prospective teachers is that in most research, only the type of observable behaviour is recorded. Corresponding quantitative features, notably the exact frequency and the time used in speaking, are not taken into account. However, the number of turns taken and the amount of speaking time used by mentor teachers may also be relevant indicators of mentor teachers' supervisory behaviour. Already in the 1970s Blumberg (1970, 1980) concluded this from research describing characteristics of mentor teachers' supervisory behaviour. More recently, Dunne and Bennett (1997) found that in terms of opportunity and time given to the student teachers to talk during mentoring dialogues, there is a definite pattern of differentiation between three types of mentors: class teachers, co-tutors and supervisors. Class teachers (mentor teachers) all contributed the greater part of verbal interaction in dialogues with student teachers. The speaking time of co-tutors tended to be more balanced with that of the student. Supervisors allowed the greater part of the speaking time to come from the student. In a study, Hughes (1998) found that on average mentor teachers' part of the verbal interaction in mentoring dialogues was $69 \%$. Hawkey $(1998$, p. 662) concluded that the type and length of the supervisor's interventions - asking questions, advising and informing or telling - gave a clear indication of the supervisor's approach: "A mentor who showed characteristics of a directive advisory approach, more typically tended towards fairly lengthy descriptions of telling the student what to do in lessons." Consequently, a more detailed and more realistic analysis of the use of different types of supervisory skills before and after training could be achieved when data are also collected about the frequencies and durations with which mentors use each of the supervisory skills distinguished.

Finally, the lack of information in the cited studies about the frequency and duration of the observed supervisory behaviour is aggravated by the use of relatively high-inference rating methods in coding the data. In most studies, questionnaires and assessment scales were used for coding relatively large chunks of supervisory behaviour. This increases the risk of subjectivity on the part of the raters. To avoid this, low-inference ratings applied to relatively small fragments of discourse were preferred in this study.

\subsection{Research questions}

The above considerations have led us to use a research design involving fine-grained measurement of the use of supervisory skills during mentoring dialogues. Based on the outlined argumentation, the following research question guided this study: Does the SMART training affect the use of supervisory skills for stimulating reflection by mentor teachers in mentoring dialogues with student teachers? This main research question was specified in three sub questions: What are, for the whole group and on an individual level, after training:

I. Shifts in frequency of use of specific supervisory skills?

II. Shifts in time spent on specific supervisory skills?

III. Relations between shifts in frequencies of use and time spent on distinct supervisory skills?

\section{Method}

\subsection{Design}

In this section, we describe the research method using the third of the "four levels of evaluation" introduced by Kirkpatrick $(1959,1998)$ for evaluating training programmes. The four levels he 
distinguishes are (1) reaction, (2) learning, (3) behaviour, and (4) results. The question to what degree and how such learning affects trainees' behaviour in the workplace is the basic issue to be evaluated on level three and the focus of this study.

The study was based on a pre- and post-test design with one group (Cook \& Campbell, 1979). Video recordings were made of mentoring dialogues, which the participating mentor teachers carried with the student teacher at that time under their guidance. Two recordings were made of each mentor teacher, one within a month before the training, the other within 1 month afterwards. The form of assessment used was a work sample test (Straetmans, 1993). In such an assessment, participants have to perform tasks in real settings, which are considered to be a sample of similar tasks in the work situation. For our respondents, this meant that they carried out a mentoring dialogue with a student teacher whom they were mentoring at the time of the study. The advantage of this setting was that the participating mentor teachers demonstrated their command of supervisory skills in a realistic situation.

\subsection{Training programme}

To answer the research question, a specific training programme focusing on teaching mentor teachers to stimulate reflection in student teachers during mentoring dialogues was evaluated. Since 1999, a training programme entitled SMART has been developed and conducted at the Department of Teacher Education of the Fontys University of Applied Sciences in the Netherlands. The focus of SMART training is developing supervisory skills for stimulating reflection (encourager role) in addition to the already (in most mentor teachers) existing supervisory skills relevant to the advisor and instructor role. The following overt supervisory skills to stimulate reflection (Korthagen, 1985, 2001) were trained: asking for concreteness, summarizing feeling (showing empathy), showing genuiness, generalizing (asking for similar situations) and helping in making things explicit, confronting (giving feedback, summarizing inconsistencies, utilizing the here and now), helping to find and to choose alternatives.

The planning and structure of the SMART programme has three main components: training, peer consultation and personal coaching. In total, the training consists of 9 sessions spread over a period of 3 months. After the introductory meeting, a series of five training sessions follows, in which the supervisory skills are practised. The two subsequent meetings are devoted to peer consultation. Here, colleagues follow a structured procedure in advising each other on situations arising from practice. In these meetings, the participants present a video of one of their own mentoring dialogues to their fellow participants and include an individual aspect that they wish to develop. After this, trainers coach the participants in their work settings, where they observe at least one mentoring dialogue and give feedback on their dialogue(s) as mentor teacher. The programme concludes with a final session with the whole group, in which the assessment results were presented and used as a basis for evaluation and certification.

The pedagogy used in the SMART programme for training mentor teachers was derived from two sources. Firstly, it draws on Koster and Korthagen (2001), who put forward the following principles of "realistic teacher education". A connection should be established between the training programme and participants' individual learning needs and questions. Using experiences from the participants' own practice trainers can make sure that the programme's contents and exercises deal with real problems. When these problems are linked with theory, analysing them can encourage participants to develop effective interventions. In this way, the contents of the exercises become relevant for all participants. Having the participants practise the skills in between training sessions helps to produce an alternation between contributing practical experiences, reflecting on them, connecting them to relevant theory and applying them to fresh situations. The same applies to systematically having participants record their own progress. Creating a safe learning environment will help participants not to be afraid of experimenting with different behaviours, both in and outside the training sessions. In this respect, mentor teacher trainers fulfil a modelling function, for example, by seeing to it that in the beginning, positive feedback is given both by themselves and by the participants among each other. The application of these principles helps in promoting constant and self-directed professional development.

Secondly, in the training programme microcounselling principles (Ivey, 1971) were used. According to this approach, skills can be learned when the following sequence of activities is used: a 
verbal or visual model giving instruction and information about a skill, practice with the aim of achieving the greatest possible similarity with the target behaviour associated with the particular skill (as described in the instruction phase) and feedback providing information and suggestions from trainer(s) on the basis of observations (coaching on the job).

\subsection{Participants}

The participants in the main study were 30 mentor teachers from primary education who participated voluntarily in the SMART training programme, 13 of the respondent group in the spring of 2002 and 17 in the spring of 2003. In total, there were 18 women and 12 men, all of whom were facilitated within their main job of teaching to guide and support student teachers in their final year of teacher training and to participate in the mentor teacher training. The student teachers were under the guidance of the participating mentor teachers between October and May. The respondents' ages ranged from 25 to 54 and averaged 44 . On average, the participants had almost 20 years of teaching experience. Not one of them had been trained in supervisory skills before. As a group, they had an average of almost 10 years of experience in mentoring student teachers.

\subsection{Instrumentation and data collection}

In the pilot phase of the project, instruments for gathering, transcribing and coding data were developed by asking 12 mentor teachers (six men and six women) in primary education who participated in the spring of 2001 in the SMART training programme to make audio recordings of two mentoring dialogues which they conducted in the workplace with student teachers under their care. The first took place at the latest 1 week before the start of training. The second took place at the latest 2 weeks after the end of training. All 24 recorded dialogues were transcribed literally from audiotape. Utterances were marked as separate using the principle of turn-taking. Then the mentor teachers' utterances were categorized from the audio verbatim using the spectrum of 15 supervisory skills described in Section 1.2. Two judges scored all 784 interventions of the mentor teachers, resulting in Cohen's kappa of 0.64 . On the basis of this pilot study, a number of improvements to the instrumentation of the main study were made.

Just as in the pilot study, in the main study we sought to standardize the setting for data collection by giving all 30 participants instructions in advance, both orally and in written form. As a first result of the recommendations from the pilot study, the mentor teachers were instructed to discuss a student concern which had arisen in the previous week and which had not been on the agenda earlier. This excluded other topics from the dialogue and allowed the mentor teachers to concentrate on those supervisory skills that they had trained in order to stimulate students to reflect on their concerns. Secondly, the mentor teachers had to conduct the dialogue with their "own" students, with whom they already have an established rapport. This was the case in the pilot study and is, in perspective of creating a natural setting, also important to do in the main study. Thirdly, the mentor teachers had to come to the teacher education building to carry out the mentoring dialogue, both before and after training. This could be done at a moment which suited them and which fitted maximally with the regular meetings they had in their school. This arrangement was made in order to increase the comparability of the physical environment in which the dialogues took place. This also enabled the researchers to achieve video registrations of uniform and sufficient quality. Fourthly, in the main study instead of audio recordings used in the pilot study, video recordings were used, so that in coding the mentor teachers' interventions, non-verbal aspects also could be considered. Finally, in order to increase comparability of the data, recordings of the dialogues were restricted to a maximum of $15 \mathrm{~min}$. In almost all recorded dialogues this was enough time to discuss the students concern. Research by Geldens, Popeijus, Peters, and Bergen (2005) indicates that dialogues between mentor teachers and student teachers which last longer than $15 \mathrm{~min}$ hardly increase the quality of the dialogues.

\subsection{Transcription, coding and analysis}

All recorded 60 dialogues in the main study were transcribed literally (Table 1). Utterances were marked as separate using the principle of turn taking. The moment a mentor teacher commences speaking marks the beginning of an intervention and the end of the student teachers' reaction. 
A mentor teacher's intervention ends at the moment the student teacher commences speaking. A particular observation instrument was used in order to research the interventions of the mentor teacher in the supervisory dialogues with the student teacher. Against the background of the comments in the introduction of this article, we have chosen to use a category system consisting of 15 overt supervisory skills, in our descriptions of the supervisory behaviour of the mentor teachers. This entails noting each behaviour as it occurs (Veenman, 1978). This ensures that in addition to a record of the type of intervention, data about the frequency and duration of the behaviour are also collected. The observation task consisted of determining when and how long the mentor teacher contributed to the dialogue and to which category the intervention belonged. The observers were prepared and trained for their task with the help of a written scoring procedure.

As a result of the experiences in the pilot study, the reliability in scoring the supervisory skills was firstly improved by delineating the scoring protocol more sharply. In the pilot study, two (or more) types of supervisory skills were sometimes performed during one turn. If this occurred in the main study, only the last type was coded, because in almost all cases this was the trigger for the student teachers' reaction. Secondly, by using a rating procedure the raters read the transcript, then viewed the video recording to consider the non-verbal aspects, and finally assigned their codes to the mentor teacher's interventions. Thirdly, three raters were used instead of two in the pilot study. All raters scored the 2274 supervisory skills the mentor teachers used in 60 dialogues that were videotaped. Cohen's kappas were raised to 0.73 between raters 1 and 2, to 0.76 between raters 2 and 3 and to 0.79 between raters 1 and 3 .

Descriptive statistics and two-tailed $t$-tests for paired observations were calculated on the data generated in this way in order to analyse the changes that occurred between the first and second measurement. In order to make a comparison between these two measurements, the metric used was the standardized mean difference ( $d$-index) effect size (ES). This metric is appropriate when the means of two groups are being compared. The $d$-index expresses the distance between two group means in terms of their common standard deviation (Cohen, 1988).

\section{Findings}

\subsection{Shifts in frequency of use of supervisory skills}

\subsubsection{Results for the whole group}

In Table 2, an overview of the results is presented. Based on the frequencies in columns 3 and 5, Fig. 1 shows the differences in frequency of use of each supervisory skill for the whole group. Before training, the mentor teachers' skills repertoire

Table 1

Example of coded transcription

\begin{tabular}{|c|c|c|c|}
\hline Time (min) & Conversation between mentor teacher and student teacher & Turn number & Skill code \\
\hline 3.39 Student teacher & $\begin{array}{l}\text { Well, you know, he was turning about all the time and talking, while there } \\
\text { wasn't anything to laugh at really, because it's quite serious. }\end{array}$ & & \\
\hline 3.48 Mentor teacher & Yes. & 9 & 1 \\
\hline 3.49 Student teacher & $\begin{array}{l}\text { The other kids are participating very seriously and then it's just like he's } \\
\text { playing the clown by joking and attracting the other kids' attention. I don't } \\
\text { know. It irritated me quite a lot. }\end{array}$ & & \\
\hline 4.04 Mentor teacher & What did you do with Ralph? & 10 & 3 \\
\hline 4.11 Student teacher & $\begin{array}{l}\text { I just continued the lesson. On the one hand, I thought, I might send him } \\
\text { off now, yes that kind of negative thing. I think that would have influenced } \\
\text { the group. Maybe on the other hand, it wasn't right that I ignored him. } \\
\text { After all, it wasn't all right what he did. Perhaps I should have pointed it } \\
\text { out to him more often, but at the time I felt: well, then you don't join in, so } \\
\text { what. }\end{array}$ & & \\
\hline 4.41 Mentor teacher & I think it's correct what you've done. & 11 & 14 \\
\hline
\end{tabular}

This table shows an example of a transcription of a dialogue between a student teacher and a mentor teacher. It is literally transcribed on the basis of turn-taking. In the left-hand column, the interlocutor is mentioned and the speaking time is given in minutes. In the second column the utterances are accurately transcribed. The number of the turn is in the third column. The fourth column shows the code used for the supervisory skill. 
Table 2

Frequencies of use of supervisory skills and amount of time spent on distinct supervisory skills, both before and after SMART training in absolute (abs.) and relative (\%) numbers

\begin{tabular}{|c|c|c|c|c|c|c|c|c|}
\hline \multirow[t]{3}{*}{ Supervisory skills } & \multicolumn{4}{|c|}{ Frequencies of use } & \multicolumn{4}{|c|}{ Time spent (s) } \\
\hline & \multicolumn{2}{|c|}{$\begin{array}{l}\text { Before SMART } \\
\text { training }\end{array}$} & \multicolumn{2}{|c|}{$\begin{array}{l}\text { After SMART } \\
\text { training }\end{array}$} & \multicolumn{2}{|c|}{$\begin{array}{l}\text { Before SMART } \\
\text { training }\end{array}$} & \multicolumn{2}{|c|}{$\begin{array}{l}\text { After SMART } \\
\text { training }\end{array}$} \\
\hline & Abs. & $\%$ & Abs. & $\%$ & Abs. & $\%$ & Abs. & $\%$ \\
\hline 01. Showing attentive behaviour & 90 & 9 & 90 & 7 & 133 & 1 & 129 & 1 \\
\hline 02. Asking an open starting question & 28 & 3 & 31 & 2 & 177 & 1 & 226 & 2 \\
\hline 03. Asking for concreteness & 154 & 16 & 399 & 31 & 1040 & 8 & 2669 & 25 \\
\hline 04. Summarizing feeling & 6 & 1 & 24 & 2 & 55 & 0 & 279 & 3 \\
\hline 05. Summarizing content & 100 & 10 & 234 & 18 & 857 & 7 & 1715 & 16 \\
\hline 06. Showing genuineness & 28 & 3 & 30 & 2 & 362 & 3 & 207 & 2 \\
\hline 07. Completing sentence/clarifying question & 26 & 3 & 36 & 3 & 110 & 1 & 122 & 1 \\
\hline 08. Confronting & 8 & 1 & 23 & 2 & 83 & 1 & 307 & 3 \\
\hline 09. Generalizing & 4 & 0 & 6 & 0 & 73 & 1 & 71 & 1 \\
\hline 10. Helping in making things explicit & 1 & 0 & 15 & 1 & 11 & 0 & 306 & 3 \\
\hline 11. Helping in finding and choosing alternatives & 39 & 4 & 87 & 7 & 554 & 4 & 1308 & 12 \\
\hline 12. Asking for something new & 85 & 9 & 99 & 8 & 1090 & 9 & 949 & 9 \\
\hline 13. Giving information & 141 & 14 & 59 & 5 & 2786 & 22 & 847 & 8 \\
\hline 14. Giving opinion/assessing & 99 & 10 & 76 & 6 & 1411 & 11 & 601 & 6 \\
\hline 15. Giving advice/instruction & 126 & 13 & 38 & 3 & 3406 & 27 & 750 & 7 \\
\hline \multirow[t]{2}{*}{ 16. Other types of interventions } & 54 & 5 & 38 & 3 & 418 & 3 & 255 & 2 \\
\hline & 989 & 100 & 1285 & 100 & 12566 & 100 & 10741 & 100 \\
\hline
\end{tabular}

consisted largely $(81 \%)$ of the following seven skills: showing attentive behaviour (9\%), asking for concreteness (16\%), summarizing content $(10 \%)$, asking for something new (9\%), giving information (14\%), giving an opinion (10\%) and giving advice/instruction $(13 \%)$. After training, these same seven skills still accounted for most of the mentor teacher behaviour $(78 \%)$.

However, a change was found in the frequencies with which these skills were used. Taken together, the interventions characterizing the advisor and instructor role (numbers 12-15) show a decrease from $46 \%$ before training to $22 \%$ after training. Supervisory skills characteristic of the advisor and instructor role, notably asking for something new $(8 \%)$, giving information (5\%), giving an opinion $(6 \%)$ and giving advice/instruction (3\%), gave way to reactions characteristic of the encourager role, notably asking for concreteness (31\%) and summarizing content $(18 \%)$. Frequencies in 'summarizing feelings' (empathy) hardly changed after training $(1 \%)$, while this was an important topic during the training programme. Similarly, interventions like confronting, generalizing and helping in making things explicit occurred relatively infrequently in the pre- and post-test (max. $2 \%$ ).
In order to test if the most important differences found were significant, those skills were selected which accounted for $10 \%$ or more of the frequency in pre- or post-test, i.e. asking for concreteness, summarizing content, giving information, giving opinion and giving advice/instruction. The (twotailed) paired samples $t$-tests $(p<0.05)$ showed that the frequencies of all five above-mentioned skills on group level differed significantly between pre- and post-test. The frequency of asking for concreteness $(\mathrm{ES}=2.00)$ and summarizing content $(\mathrm{ES}=0.96)$ increased and the frequency of giving information ( $\mathrm{ES}=1.09)$, giving opinion $(\mathrm{ES}=0.56)$, and giving advice/instruction $(\mathrm{ES}=0.89)$ decreased. These are all large ESs (Cohen, 1988).

\subsubsection{Differences on the individual level}

Fig. 2 shows that there are definite individual differences between the subjects. To illustrate this, we can zoom in on asking for concreteness, one of the five supervisory skills where there is a significant change in all members of the group and which shows the highest frequency in use, both before and after the training.

An participants example of individual differences is that of participants 11 and 26. The black squares 


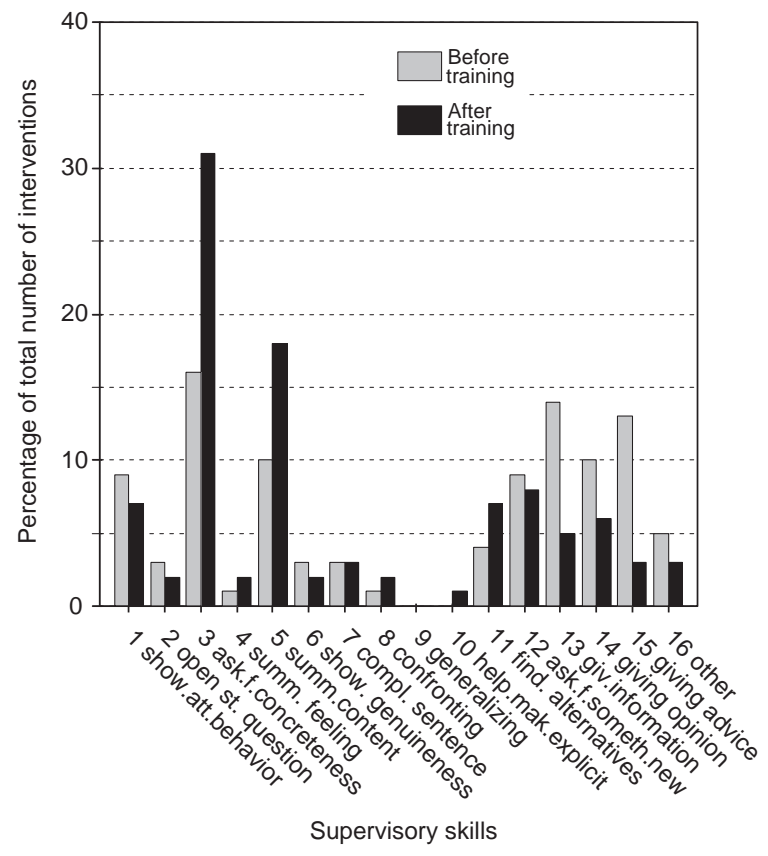

Fig. 1. Shifts in frequency of use of specific supervisory skills. The horizontal axis indicates the 15 supervisory skills detailed in this study. The rest category includes interventions unable to be assessed. The vertical axis denotes the frequency of use of distinct supervisory skills as a percentage of the total number of interventions on group level. The grey bar denotes the frequency of use of the skills before training, while the black bar denotes this frequency after training.

indicate that in measurements taken after the training in both participants, more than $25 \%$ of the supervisory skills consist of asking for concreteness. The white squares show that there are large individual differences in the use of this skill, as measured before training. After training we can see that there is a relatively small decrease in this use in participant 11 , and in participant 26 there is actually a relatively large increase.

Another notable example of individual differences can be seen between participants 7 and 9 . In participant 7 , we can see that in the measurements before the training there is a high frequency in asking for concreteness, which increases slightly after training. In participant 9, there is a lower frequency, which increases substantially after the training.

\subsection{Shifts in time spent on specific supervisory skills}

\subsubsection{Results for the whole group}

Fig. 3 shows the differences in total time spent on distinct supervisory skills for the whole group.

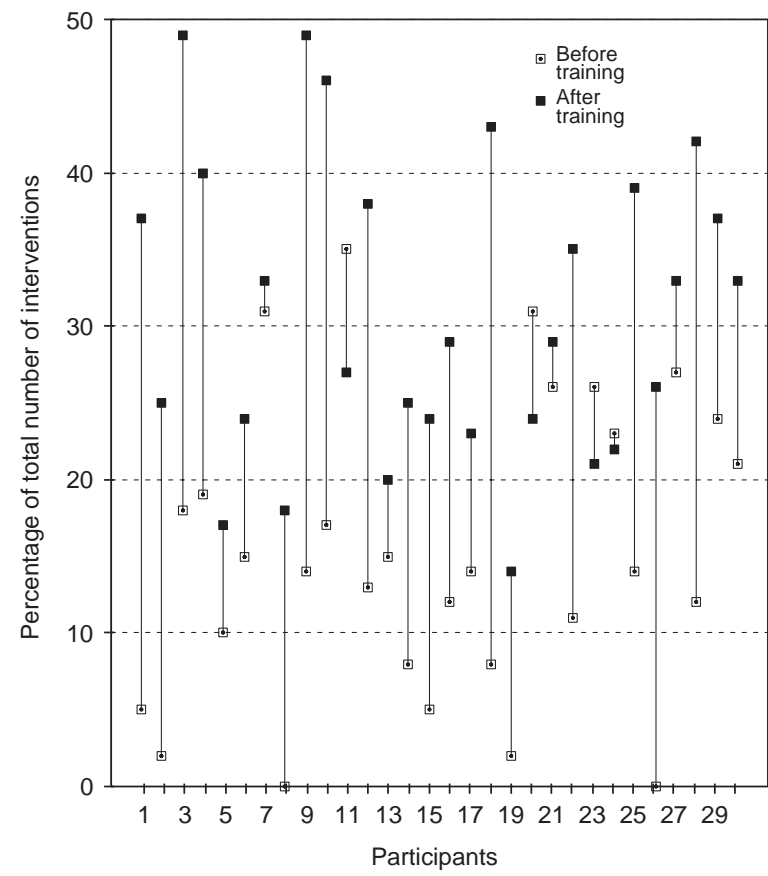

Fig. 2. Shifts in frequencies of "Asking for concreteness". All the participants are shown on the horizontal axis. The vertical axis shows the frequency of the intervention "Asking for concreteness", calculated as a percentage of the total number of interventions used by one participant. The white squares denote the frequency of use before and the black squares refer to use after training. The length of the line indicates the changes in frequency.

Before training, the group of mentor teachers spent $88 \%$ of their speaking time on a repertoire of seven distinct supervisory skills: asking for concreteness (8\%), summarizing content (7\%), helping to find and to choose alternatives (4\%), asking for something new (9\%), giving information (22\%), giving an opinion (11\%) and giving advice/instruction (27\%). After training, these seven skills still accounted for most of the mentor teachers' speaking time $(83 \%)$.

However, a change was found in the time spent using these skills. Taken together, the interventions characterizing the advisor and instructor role (numbers 12-15) show a decrease from $69 \%$ before training to $30 \%$ after training. Supervisory skills characteristic of the advisor and instructor role, notably asking for something new (9\%), giving information $(8 \%)$, giving an opinion $(6 \%)$ and giving advice/instruction (7\%), gave way to reactions characteristic of the encourager role, notably asking for concreteness (25\%) and summarizing content $(16 \%)$ and helping to find and to choose alternatives $(12 \%)$. 


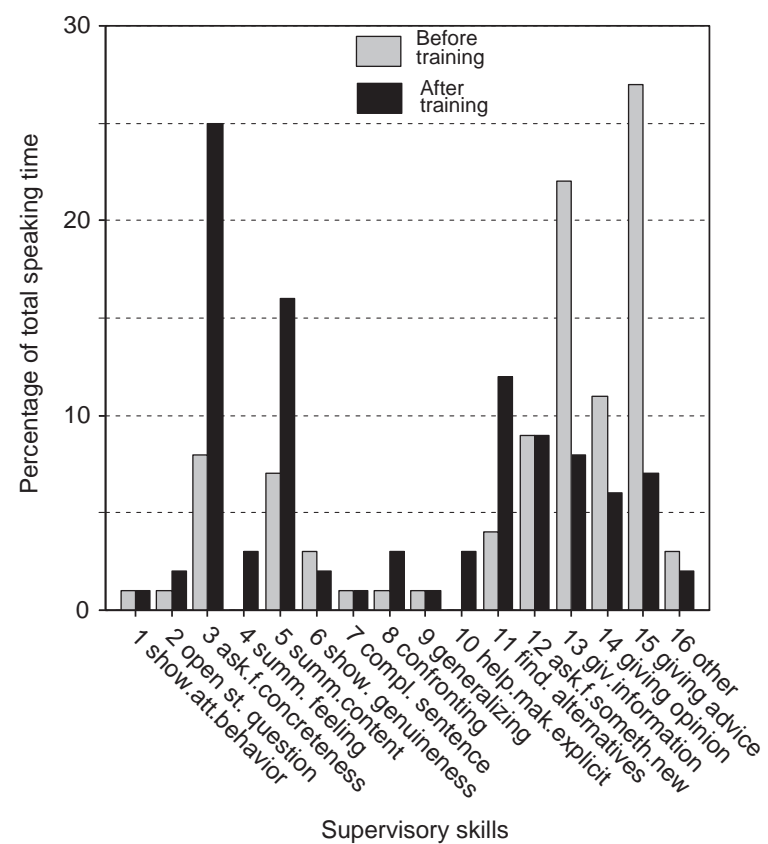

Fig. 3. Shifts in total time spent on specific supervisory skills. The horizontal axis indicates the 15 supervisory skills distinguished in this study. The vertical axis denotes the time the whole group mentor teachers spent on distinct skills as a percentage of the total speaking time of the group mentor teachers. The left grey bar denotes the situation before training and the right black bar denotes the situation after training.

In order to test if the most important differences found were statistically significant, those skills were selected which accounted for $10 \%$ or more of the time spent in pre- or post-test, i.e. asking for concreteness, summarizing content, helping to find and to choose alternatives, giving information, giving opinion and giving advice/instruction. The (twotailed) paired sampled $t$-tests $(p<0.05)$ showed that the time spent on four of the above-mentioned skills on group level differed significantly between preand post-test. The shift in time spent on giving opinion was not statistically significant. The time spent on asking for concreteness (ES =1.61), summarizing content $(\mathrm{ES}=0.81)$ and helping to find and to choose alternatives $(\mathrm{ES}=1.14)$ increased significantly. The time spent on giving information $(\mathrm{ES}=0.99)$ and giving advice/instruction decreased significantly $(\mathrm{ES}=1.5)$. These are all large ESs (Cohen, 1988).

\subsubsection{Differences on the individual level}

Fig. 4 shows that there are also individual differences between mentor teachers with reference to changes in the amount of time devoted to specific

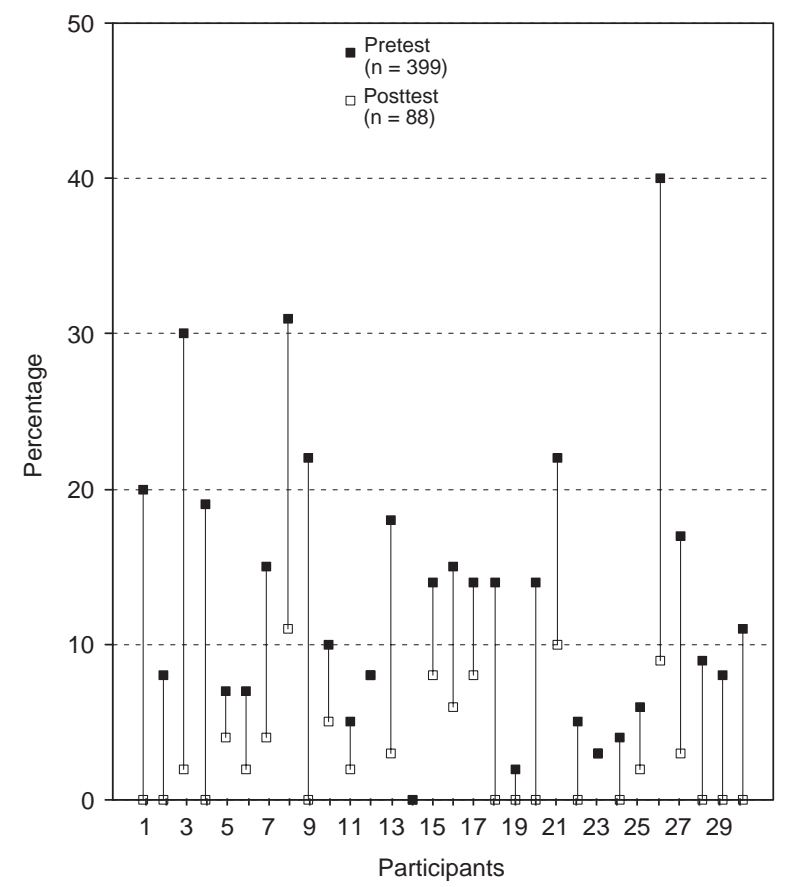

Fig. 4. Shifts in time spent on "Giving advice". All the participants are shown on the horizontal axis. The vertical line denotes the amount of time spent by each participant on the intervention "Giving advice" and is given as a percentage of the total speaking time. The white squares denote the time spent before training and the black squares refer to after training. The length of the line indicates the changes in the time spent.

supervisory skills. To illustrate this, we can zoom in on giving advice/instruction, the skill which the group spent a lot of time on in their mentoring dialogues. It was interesting to note that there is a subgroup that scores very highly in the use of this skill in measurements taken before the training, but that this dramatically decreased after the training. Also, there are clear differences between the members of this subgroup. This can be illustrated by participants 12 and 13. A second subgroup consists of mentor teachers who in the pre-test spent relatively little time on giving advice/instruction. Overall in this group, we see in the post-training measurements a limited decrease. Only 3 participants (1, 17 and 25) show an increase in the time spent on giving advice/instruction.

\subsection{Relations between shifts in frequencies and time spent}

Fig. 5 shows how the mentor teachers' total speaking time and their frequency of turn-taking changed. The shift concerning the frequency of 


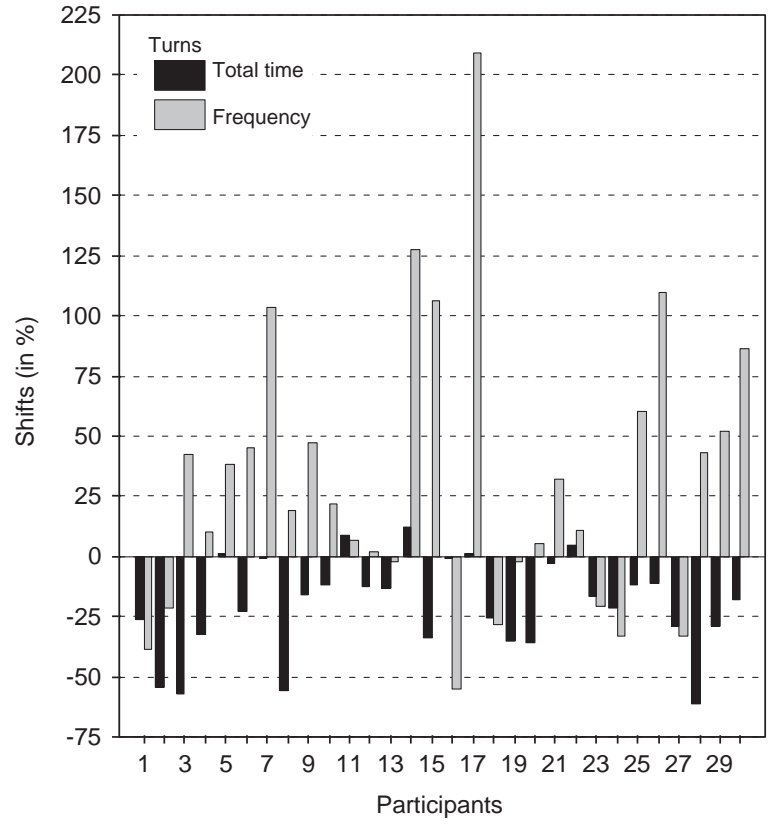

Fig. 5. Shifts in speaking time and frequency of turn-taking before and after training. All the participants are shown on the horizontal axis. The vertical axis shows two changes. The black bars represent for each participant the changes in speaking time as a percentage of the total speaking time. The grey bars represent for each participant the changes in frequency of turn-taking as a percentage of the total number of turns.

turn-taking was calculated by dividing the total number of turns taken after training minus the total number of turns taken before training by the total number of turns taken before training. For example, before training participant 3 uses 40 interventions and after training 57 . The percentile change according to the formula is $(57-40) / 40=+43 \%$. In Fig. 5, this increase is represented by the grey bar above the $0 \%$ line. $^{1}$

\footnotetext{
${ }^{1}$ In order to compare data on the frequency of turn-taking of the 30 mentor teachers in the pre- and post-test, we have extrapolated from the results. In 20 participants, the mentoring dialogues were shorter than the suggested $15 \mathrm{~min}$ : on average 12 min with a range from 7 to $14 \mathrm{~min}$. After training, 10 mentors used less than the suggested $15 \mathrm{~min}$ an average of $14 \mathrm{~min}$ with a range from 11 to $14 \mathrm{~min}$. With all mentoring dialogues that lasted shorter than $15 \mathrm{~min}$, a certain number of turns have been added. This took place using the same percentage necessary to fill the actual time taken and increased it to the allocated $15 \mathrm{~min}$. The assumption for this calculation is that there is a linear connection between the total time and the number of turns. Hence, for example, if a dialogue actually took $12 \mathrm{~min}$, then $3 \mathrm{~min}(25 \%)$ have been added in order to come to the full $15 \mathrm{~min}$. This means that if the mentor used 32 turns in $12 \mathrm{~min}$, this would be increased by $25 \%$ to 40 turns.
}

Fig. 5 also shows the changes observed in the mentor teachers' total speaking time. The shift concerning the total speaking time was calculated by dividing the total speaking time after training (in \%) minus the total speaking time before training (in $\%$ ) by the total speaking time before training (in \%). For example, before training participant 3 was speaking for $52 \%$ of the time and after training this went down to $22 \%$. The percentile change in the speaking time of this mentor teacher has been calculated using the above formula: $(22-52 \%) /$ $52 \%=-57 \%$. In Fig. 5, this decrease is represented by the third black bar (participant 3 ).

\subsubsection{Results for the whole group}

After training, in most of the mentor teachers, an increase in the number of turns, on the one hand, and a decrease in speaking time, on the other hand, was observed. The frequency of turn-taking increased on average from 37 to 44 turns. This is a statistically significant increase of $19 \%$ for the whole group $(p<0.05, \mathrm{ES}=0.63)$. The grey bars in Fig. 5 show that 21 mentor teachers showed an increase with a range between $2 \%$ and $210 \%$ and nine mentor teachers showed a decrease of turn taking with a range between $2 \%$ and $55 \%$. At the same time, mentor teachers' total speaking time decreased on average from $53 \%$ to $41 \%$. This is a statistically significant percentile change of $23 \%$ $(p<0.05, \mathrm{ES}=1.02)$. The black bars in Fig. 5 show that the total speaking time of 25 mentor teachers decreased (range between $1 \%$ and $61 \%$ ) and that the total speaking time of 5 mentor teachers increased (range between $1 \%$ and $12 \%$ ).

In order to understand better the relationship between the changes observed in frequency and duration of distinct supervisory skills in the group of mentor teachers, we took the average as a measurement. The overall average time the group mentor teachers used separately for each turn decreased from $14 \mathrm{~s}$ in the pre-test to $9 \mathrm{~s}$ in the post-test. This is a statistically significant percentile decrease of $35 \%(p<0.01, \mathrm{ES}=1.07)$. In order to ascertain which specific skills underlay the decrease, average times were calculated for those supervisory skills whose variation in frequency and time spent between the pre- and the post-test proved statistically significant. This calculation of the averages gave the following results: giving opinion (from 15 to $9 \mathrm{~s}$ ), giving information (from 20 to $15 \mathrm{~s}$ ) and giving advice/instruction (from 28 to $19 \mathrm{~s}$ ) both before and after training took longer per turn than asking for 
concreteness (7 and $7 \mathrm{~s}$ ) and summarizing content (from 7 to $8 \mathrm{~s}$ ).

The use of asking for concreteness and summarizing content changes dramatically as far as the total number of turns is concerned (see Fig. 1), but not as far as the duration of each turn is concerned. The supervisory skills of giving information and giving advice/instruction change in both the total number of turns (see Fig. 1) and the average speaking time per turn. The fact that after the training the mentor teachers were on average using less speaking time and yet more turns is linked to the length of duration of both asking for concreteness and summarizing content remaining constant while the frequency increased. The skills giving information and giving advice/instruction meanwhile decreased in frequency and also in length of duration.

\subsubsection{Differences on the individual level}

On average participants use more turns but less speaking time in the mentoring dialogues after training. There were some participants for whom this is not the case (examples of participants 1, 2 and 27). The majority of the group fits in the above mentioned trend, although there are individual differences in intensity of the increase and decrease of speaking time and number of turns.

\section{Conclusion and discussion}

\subsection{Conclusion}

This study adds to our knowledge about the effects of training programmes to increase supervisory skills for the benefit of student teachers. It shows the effect of the SMART training programme on the use of mentor teachers' supervisory skills in mentoring dialogues. The study has produced evidence that it is possible to increase the use of supervisory skills for promoting reflection in student teachers, even though there were substantial differences between participants. The observed change in mentor teachers' supervisory behaviour provides opportunities for mentor teachers to practise not only the advisor and instructor role, but also the encourager role. For student teachers, this may create opportunities to introduce and explore their concerns in a more reflective manner in dialogues with their mentor teachers.

Specifically, the breadth of the supervisory skills repertoire of the mentor teachers studied hardly changed after the training. However, in their basic repertoire, a shift was found in the frequencies with which they used the supervisory skills. In mentoring dialogues held after training, the number of interventions taking the mentor teacher's perspective as a starting point (advisor and instructor role) decreased in favour of interventions taking the student's perspective as a starting point (encourager role). This result was confirmed by the fact that after training, less time was spent on supervisory skills characteristic for the advisor and instructor role, while the time spent on skills characteristic for the encourager role increased.

After the SMART training, mentor teachers on average used less of the dialogue time as well as taking more conversational turns. Those types of supervisory skills whose frequencies decreased require relatively much time, because in using these, the mentor teacher is often elaborating and explaining. Those types of interventions whose frequencies increased take relatively less speaking time, because here, brief questions and reactions are involved. For example, asking for concreteness does not take as much time as giving advice/instruction. Using asking for concreteness more then logically leads to a decrease in the average duration of interventions. All in all, these shifts show that after SMART training mentor teachers created more opportunities for the student teachers to participate more actively in the mentoring dialogue.

\subsection{Limitations}

This study involved precise quantitative ratings of small units of supervisory behaviour during mentoring dialogue. Admittedly, this is a reduction, but this reduction enabled us to identify shifts in supervisory behaviour as observed before and after training. At the same time, there are probably other factors than the training that influenced the presence or absence of differences in mentor teachers' behaviour as measured between pre- and post-test as well as between participants. Firstly, the fact that participants scored better in relation to the training goals at the post-test may have to do with diminished tension. At that time, they were more familiar with the test conditions, the researchers and the trainers. This is a possible reason as to why some participants experienced fewer negative effects on their performance. Secondly, the individual differences in supervisory skills found between participants may have been caused by the fact that the training content and approach is the same for all 
participants, whilst their needs and skill levels were possibly different. One participant could learn more than another, or less, which means that the effects of training as measured would be reduced in size. Thirdly, the fact that not all trained supervisory skills were observed in the behaviour of the mentor teachers could have to do with the different levels of difficulty, with the timing and execution of the trained supervisory skills. For example, most mentor teachers seem to find it easier to pick up the intervention asking for concreteness than to use summarizing inconsistencies or helping in making things explicit. Fourthly, limited effects seen on some of the trained supervision skills could be due to the fact that only mentor teachers who were experienced in supervising students took part in the training. They have already developed particular behaviours in supervising, which in general are those of an advisory nature, and which are difficult to change. Finally, it could be that skills which were trained but were not observed in the post-test were not always appropriate for use in the dialogues that were recorded.

Despite these limitations, the conclusion of this study that effects of SMART training on the supervisory repertoire of mentor teachers occur seems justified. This is supported by earlier effect studies, as described in Section 1.3, where some effects, although sometimes limited and diverse, are reported. The conclusion is also supported by reviews of effect studies in other contexts. These reviews, covering over 300 (quasi-) experimental studies into the effects of training on interpersonal and communication skills - related to supervisory skills used by mentor teachers - in the mental, social and physical health sectors, all conclude that effect of training on behaviour can be established to some degree (Baker \& Daniels, 1989; Baker, Daniels, \& Greeley, 1990; Carol \& Monroe, 1980; Ford, 1979; Hulsman, Ros, Winnubst, \& Bensing, 1999; Kruijver, Kerkstra, Francke, Bensing, \& Van de Wiel, 2000; Kurtz, Marshall, \& Banspach, 1985; Van der Molen, Smit, Hommes, \& Lang, 1995).

\subsection{Directions for future research}

In concluding this article, we suggest directions for future research. First, an interesting finding was that some participants spontaneously reported that after training they paid more conscious attention to their own supervisory behaviour during mentoring dialogues. More specifically, participants reported that they experienced something like a dual cognitive task during dialogues: following the student teachers' input and at the same time considering how to align their own interventions to this input. This could amount to an effect of training on participants' (meta) cognitions during mentoring dialogues as a mediating factor in the transfer of training to supervisory behaviour. To get more insight into the process of transfer, it would be interesting to try and capture effects of a training programme for mentor teachers that occur in the minds of the participants during the mentoring dialogue. Secondly, it should be noted that follow-up studies are so far lacking. We consider it important to ascertain whether training can positively affect the use of supervisory skills for stimulating reflection and whether these skills can be retained in the longer run. Thirdly, the recorded differences in effects of training among the participants beg the question of how much influence variables outside the training have on the results. Holton and Baldwin (2000) developed a model in which the potential influences of characteristics of trainees and features of the workplace are identified. Research incorporating such variables may consider whether it makes sense to select candidates for training programmes on the basis of personal characteristics and/or opportunities and facilities in the work setting for using the acquired skills in daily practice. Fourthly, if, as this study shows, training in supervisory skills can influence the behaviour of mentor teachers, this leads to the next question whether and how student teachers perceive this change in behaviour during the mentoring dialogues. Follow-up research could consider the effects of training from the point of view of the student teachers. After all, the final goal of developing a more versatile repertoire of supervisory skills is that it serves the learning of their student teachers.

\section{References}

Baker, S. B., \& Daniels, T. G. (1989). Integrating research on the microcounseling programme: A meta-analysis. Journal of Counseling Psychology, 36, 213-222.

Baker, S. B., Daniels, T. G., \& Greeley, A. T. (1990). Systematic training of graduate level counselors: Narrative and metaanalytic reviews of three major programs. Counseling Psychologist, 18, 355-421.

Blumberg, A. (1970). Supervisor-teacher relationships: A look at the supervisory conference. Administrator's Notebook, Midwest Administration Center University, Chicago, Vol. XIX (1)

Blumberg, A. (1980). Supervisors \& teachers: A private cold war. Berkeley: McCutchan. 
Borko, H., \& Mayfield, V. (1995). The roles of the cooperating teacher and university supervisor in learning to teach. Teaching and Teacher Education, 11, 501-518.

Borko, H., \& Putnam, R. T. (1995). Expanding a teacher's knowledge base: A cognitive psychological perspective on professional development. In T. R. Guskey, \& M. Huberman (Eds.), Professional development in education: New paradigms and practice (pp. 35-65). New York: Teachers College Press.

Boydell, D. (1991). Issues in teaching practice supervision research: A review of literature. In L. Katz, \& J. Raths (Eds.), Advances in teacher education, Vol. 4. Norwood, NJ: Ablex.

Brammer, L. M. (1973). The helping relationship: Process and skills. Englewood Cliffs, NJ: Prentice-Hall.

Carkhuff, R. R. (1969). Helping and human relations, Vol. 1. New York: Holt, Rinehart \& Winston.

Carol, J. G., \& Monroe, J. (1980). Teaching clinical interviewing in the health professions. Evaluations of the Health Professions, 3, 21-45.

Cohen, J. (1988). Statistical power analysis for the behavioural sciences. Hillsdale, NJ: Erlbaum.

Cook, T. D., \& Campbell, D. T. (1979). Quasi-experimentation, design, analysis issues for field settings. Boston: Houghton Miffin.

Copeland, W. D. (1982). Student teachers' preference for supervisory approach. Journal of Teacher Education, 33(2), 32-36.

Costa, A. L., \& Garmston, R. J. (1994). Cognitive coaching: A renaissance school. Norwood: Christopher-Gordon.

Dart, P., \& Drake, L. (1995). Mentoring English and mathematics. In I. Reid, M. Constable, \& R. Griffiths (Eds.), Teacher education reform, current research. London: Paul Chapman.

De Jong, J. A. (2004). De praktijk is total anders. Principes en varianten van het gebruik van werkervaring in opleidingen [Practice is totally different. Principles and variations in using work experiences in education]. In J. Streumer, \& M. van der Klink (Eds.), Leren op de werkplek (Learning in the workplace) (pp. 51-70). Den Haag: Reed Business Information.

Dolk, M. (1997). Onmiddellijk onderwijsgedrag. Over denken en handelen van leraren in onmiddelijke onderwijssituaties [Immediate teaching behaviour: On teacher knowledge and behaviour in immediate teaching situations]. Doctoral dissertation, Utrecht University, Utrecht.

Dunn, T. G., \& Taylor, C. A. (1993). Cooperating teacher advice. Teaching and Teacher Education, 9(4), 411-423.

Dunne, E., \& Bennett, N. (1997). Mentoring processes in schoolbased training. British Educational Research Journal, 23, 225-237.

Edwards, J., \& Green, K. (1999). Growth in coaching skills over a three-year period: Progress towards mastery. Paper presented at the Annual meeting of the American Educational Research Association, Montreal, Canada (April).

Egan, G. (1975). The skilled helper: A model for systematic helping and interpersonal relating. Pacific Grove, CA: Brooks/Cole.

Eraut, M. (2000). Non-formal learning and tacit knowledge in professional work. British Journal of Educational Psychology, 70(Part I), 113-136.

Evertson, C. M., \& Smithey, M. W. (2001). Mentoring effects on protégé classroom practice. Journal of Educational Research, 93(5), 294-304.
Feiman-Nemser, S. (2000). From preparation to practice, designing a continuum tot strengthen and sustain teaching. Teachers College Record, 103(6), 1013-1055.

Feiman-Nemser, S. (2001). Helping novices learn to teach. Lessons form an exemplary support teacher. Journal of Teacher Education, 51(1), 17-30.

Field, B., \& Field, T. (1994). Teachers as Mentors: A practical guide. London: The Falmer Press.

Ford, J. D. (1979). Research on training counselors and clinicians. Review of Educational Research, 49, 87-130.

Franke, A., \& Dahlgren, L. O. (1996). Conceptions of mentoring: An empirical study of conceptions of mentoring during the school-based teacher education. Teaching and Teacher Education, 12(6), 627-641.

Furlong, J., \& Maynard, T. (1995). Mentoring student teachers. The growth of professional knowledge. London: Routledge.

Geldens, J., Popeijus, H., Peters, V., \& Bergen, Th. (2005). Mentoring met kwaliteit als krachtig kenmerk van werkplekomgevingen voor aanstaande leraren. Analyseresultaten van mentoringsgesprekken [The quality of mentoring as a feature of effective workplace environments for prospective teachers. Analyzing results of mentoring dialogues]. Paper presented at the Onderwijs Research Dagen, Gent, Belgium (May).

Giebelhaus, C. R., \& Bowman, C. L. (2002). Teaching mentors: Is it worth the effort? Journal of Educational Research, 95(4), 246-254.

Glickman, C. (1981). Developmental supervision: Alternative practices for helping teachers improve instruction. Alexandria, VA: Association for Supervision and Curriculum Development.

Goldhammer, R. (1969). Clinical supervision: Special method for the supervision of teachers. New York: Holt, Rinehart and Winston.

Gore, J. M., \& Zeichner, K. M. (1991). Action research and reflective teaching in pre-service teacher education. Teaching and Teacher Education, 7(2), 119-136.

Haggarty, L. (1995). The use of content analysis to explore conversations between school teacher mentors and student teachers. British Educational Research Journal, 21(2), 183-197.

Harrison, J., Lawson, T., \& Wortley, A. (2005). Mentoring the beginning teacher: Developing professional autonomy through critical reflection on practice. Reflective Practice, 6(3), 419-441.

Hawkey, K. (1998). Mentor pedagogy and student teacher professional development: A study of two mentoring relationships. Teaching and Teacher Education, 14(6), 657-670.

Holton, E. F., \& Baldwin, T. T. (2000). Making transfer happen: An action perspective on learning transfer systems. Advances in Developing Human Resources, 8, 1-6.

Hughes, M. (1998). Developing the use of qualitative analysis to describe and explore the effectiveness of post-observational discourse between school-based mentors and students in teacher education. Paper presented at the European conference on educational research, Ljublljana, Slovenia.

Hulsman, R. L., Ros, W. J. G., Winnubst, J. A. M., \& Bensing, J. M. (1999). Teaching clinically experienced physicians communication skills. A review of evaluation studies. Medical Education, 33, 655-668.

Ivey, A. (1971). Microcounseling: Innovations in interviewing training. Springfield, IL: Thomas. 
Joyce, B., \& Showers, B. (1982). The coaching of teaching. Educational Leadership, 40(10), 4-8.

Kagan, D. (1992). Professional growth among pre-service beginning teachers. Review of Educational Research, 62, $129-169$

Kirkpatrick, D. L. (1959). Techniques for evaluating training programs. Journal of the American Society of Training Directors, 13(59), 3-9.

Kirkpatrick, D. L. (1998). Evaluating training programs. San Francisco: Berrett-Koehler.

Koetsier, C. P., \& Wubbels, J. T. (1995). Bridging the gap between initial teacher training and teacher induction. Journal of Education for Teaching, 21(3), 333-345.

Korthagen, F. A. J. (1985). Reflective teaching and pre-service teacher education in The Netherlands. Journal of Teaching Education, 36(5), 11-15.

Korthagen, F. A. J. (1988). The influence of learning orientations on the development of reflective teaching. In J. Calderhead (Ed.), Teachers' professional learning (pp. 35-50). London: Falmer Press.

Korthagen, F. A. J. (1998). De reflectieve organisatie. Naar een systematiek in de relatie tussen werken en leren [The reflective organisation. Towards a systematic relation between work and learning]. Handboek Effectief Opleiden [Handbook of Effective Training] (pp. 121-140).

Korthagen, F. A. J. (2001). Helping individual teachers become reflective. In F. A. J. Korthagen (Ed.), Linking practice and theory: The pedagogy of realistic teacher education (pp. 108-130). Mahwah, NJ: Lawrence Erlbaum.

Koster, B., \& Korthagen, F. A. J. (2001). Training teacher educators for the realistic approach. In F. A. J. Korthagen (Ed.), Linking practice and theory: The pedagogy of realistic teacher education (pp. 239-253). Mahwah, NJ: Lawrence Erlbaum.

Koster, B., Wubbels, J. T., Korthagen, F. A. J., \& Somers, T. (1996). Restructuring teacher education: The professionalization of mentor teachers. Utrecht: IVLOS Utrecht University (Unpublished manuscript).

Kruijver, I. P. M., Kerkstra, A., Francke, A. L., Bensing, J. M., \& Van de Wiel, H. B. M. (2000). Evaluation of communication training programs in nursing care: A review of literature. Patient Education and Counseling, 39(1), 129-145.

Kurtz, P. D., Marshall, E. K., \& Banspach, S. W. (1985). Interpersonal skill training research: A 12 year research and analysis. Counsellor Education and Supervision, 249-263.

Laboskey, V. K. (1994). A conceptual framework for reflection in pre-service teacher education. In J. Calderhead, \& P. Gates (Eds.), Conceptualising reflection in teacher development. London: Falmer Press.

Licklider, B. L. (1995). The effects of peer coaching cycles on teacher use of complex teaching skill and teachers' sense of efficacy. Journal of Personnel Evaluation in Education, 9(1), 55-68.

Martin, S. (1994). The mentoring process in pre-service teacher education. School Organization, 14, 269-277.
Martin, S. (1996). Support and challenge: Conflicting or complementary aspects of mentoring novice teachers. Teachers and Teaching, 2(1), 41-56.

McLennan, N. (1995). Coaching and mentoring. Gower: Aldershot.

Oosterheert, I., \& Vermunt, J. (2001). Individual differences in learning to teach: Relating cognition, regulation and affect. Learning and Instruction, 11, 133-156.

Pajak, E. (1993). Approaches to clinical supervision: Alternatives for improving instruction. Norwood: Christopher Gordon.

Riggs, I. M. (2000). The impact of training and induction activities upon mentors as indicated through measurement of mentor self efficacy. Research Report, California State University, San Bernardino.

Rodgers, C. (2002). Defining reflection: Another look at John Dewey and reflective thinking. Teachers College Record, 104(4), 842-866.

Rogers, C. R. (1969). Freedom to learn. Columbus, OH: Merrill.

Straetmans, G. (1993). Effectevaluatie: elementaire ontwerprichtlijnen [Effect evaluation: Elementary design procedures] Handboek Effectief Opleiden [Handbook of effective training] (pp. 133-145).

Strong, M., \& Baron, W. (2004). An analysis of mentoring conversations with beginning teachers: Suggestions and responses. Teaching and Teacher Education, 20, 47-57.

Timperley, H. (2001). Mentoring conversations designed to promote student teacher learning. Asia-Pacific Journal of Teacher Education, 29(2), 111-123.

Van der Molen, H. T., Smit, G. N., Hommes, M. A., \& Lang, G. (1995). Two decades of cumulative microteaching in The Netherlands: An overview. Educational Research and Evaluation, 1(4), 347-378.

Van Ginkel, G. V. M., Vermunt, J. D., Verloop, N., \& Beijaard, D. (2005). Conceptions of mentoring and learning to teach in Dutch secondary student teaching. Paper presented at the European Association for Research in learning and instruction, Nicosia, Cyprus (August).

Veenman, S. (1978). Interactie analyse [Interaction analysis]. Onderwijskundig [Educational] Lexicon, DH 2300-1. Alphen a/d Rijn: Samson.

Veenman, S., \& Denessen, E. (2001). The coaching of teachers: Results of five training studies. Educational Research and Evaluation, 7(4), 385-417.

Vonk, J. H. C. (1993). Mentoring beginning teachers: Mentor knowledge and skill. Mentoring, 1(1), 31-41.

Vonk, J. H. C. (1996). Conceptualizing the mentoring of beginning teachers. Paper presented at the Annual conference of the American Educational Research Association, New York.

Vrolijk, A. (1991). Gesprekstechniek [Interview Technique]. Houten: Bohn Stafleu Van Loghum.

Williams, E. A., Butt, G. W., Gray, C., Leach, S., Marr, A., \& Soares, A. (1998). Mentors' use of dialogue within a secondary initial teacher education partnership. Educational Review, 50(3), 225-239. 